\title{
EL DISCURSO LITERARIO COSTARRICENSE SOBRE \\ ENFERMEDAD MENTAL Y LOCURA FEMENINA (1890-1914)
}

\author{
Bach. Ileana D'Alolio \\ Estudiante de la Licenciatura en Historia \\ Universidad de Costa Rica
}

\section{RESUMEN}

Este artículo analiza el contenido del discurso de la literatura costarricense, con el fin de identificar las variantes de las nociones sobre enfermedad mental y locura femenina entre 1890 y 1914. Período el cual, el Estado liberal se acerca más al ideal liberal clásico, y se desarrolla una relación conflictiva al interior del círculo de intelectuales, a partir de la cual se renueva el proyecto de sociedad. En este contexto, aparecen las nociones sobre locura y padecimiento mental, las cuales responden a la dinámica conflictiva de la construcción de las relaciones de género y de la "cuestión social."

Descriptores: Mujeres y hombres. Género. Enfermedad mental. Locura. Cuestión social. Intelectuales. Liberales. Estado. Costa Rica. Fines siglo XIX y principios del siglo XX.

\section{INTRODUCCIÓN}

Este trabajo estudia el contenido del discurso de la literatura costarricense en la transición hacia el siglo XX, con el fin de identificar las variantes de las nociones sobre enfermedad mental y locura femeninas entre 1890 y 1914. En este período, el Estado liberal se acerca más al ideal liberal clásico (Palmer 1999: 101), se desarrolla una relación conflictiva al interior del círculo de intelectuales, a partir de la cual se renueva el proyecto de sociedad. En este contexto, aparecen las nociones sobre locura y 
padecimiento mental, las cuales responden a la dinámica conflictiva de la construcción de las relaciones de género y de la "cuestión social." Las fuentes utilizadas se circunscriben a los textos literarios -libros y folletos- producidos entre 1890 y 1914, dejando de lado las primeras incursiones de algunos intelectuales en el campo de la investigación científica o filosófica. Su contenido se evaluó utilizando el método de análisis de contenido abierto que permite fijar amplias categorías de análisis para responder a las preguntas de investigación.

Durante la segunda mitad del siglo XIX, Costa Rica logró vincularse al mercado mundial con la colocación del café como principal producto de exportación y consolidar una economía agroexportadora. A lo largo de este proceso se dio una aceleración en la privatización de la tierra, un aumento en la oferta y demanda de trabajo, y una expansión del crédito (Molina 1995: 169). También se consolidó una burguesía cafetalera que se preocupó por controlar el crédito con la apertura de bancos en la región, y de diversificar sus intereses invirtiendo primero en la producción de banano y posteriormente en azúcar, cacao, ganadería, minería y en la pequeña industria (Molina y Palmer 1997: 60-62). A raíz del auge en la economía, los patrones de consumo de esta pequeña burguesía se modificaron, se dio una predilección por los bienes materiales y culturales europeos (Fumero 1992: 93-104). Mediante la secularización y centralización del poder político este sector burgués -que mantenía un estrecho vínculo con la cultura material extranjera y las ideologías de la Ilustración, la Economía Política, el liberalismo y la masonería (Molina 1995: 170)-, ocupó un espacio dentro del Estado y logró llevar a cabo un proyecto civilizador basado en reformas positivistas. Las Reformas Liberales, produjeron 
un cambio cultural importante al intentar conciliar los proyectos de modernización y progreso económico con el ideario del orden social.

La comunidad intelectual costarricense -de origen criollo y extranjero- participó al lado del Estado en la tarea de secularizar y "civilizar" las prácticas y creencias de la cultura popular mediante un proceso gradual de cambio. Las Reformas Liberales fueron planteadas por estos intelectuales cuyas ideas estaban fuertemente influenciadas por el liberalismo, el positivismo y el racionalismo, por lo que a menudo hacían referencia a conceptos como "observación", "experiencia", "sistema" o "punto de vista científico" (Morales 1993: 76). La secularización y la liberalización de la cultura constituían los medios más importantes para alcanzar el "mundo moderno." Estas reformas, realizadas entre 1884 y 1888 , produjeron cambios importantes en el ámbito jurídico y extendieron el aparato educativo, a la vez que promovieron la organización de instituciones y "centros de cultura" que garantizaban la circulación de las nuevas ideas (Molina 1993: 78-80). El Estado liberal se encargó entonces, de difundir los valores burgueses a través de diversos medios que facilitaran la secularización de la sociedad; uno de ellos fueron las publicaciones estatales de folletos agrícolas, históricos y geográficos y posteriormente de higiene (Molina 1995: 172).

En las primeras décadas del siglo $\mathrm{XX}$, aparecieron una serie de instituciones destinadas a la previsión y protección social. Con una lógica interna propia e inspiradas en proyectos de beneficencia, filantropía, derecho y medicina, estas instituciones trabajaron a partir de nociones positivistas y organicistas, y en su desarrollo intervino un grupo de intelectuales reformadores y positivistas, que promovieron la participación estatal en las cuestiones sociales. En este proceso social de aplicación de la terapéutica 
liberal, el aparato estatal adquirió conocimientos sobre las clases populares a la vez que las instruía en los valores burgueses, de higiene, salud y trabajo, validando nuevas normas sociales y morales y jerarquías raciales y sexuales (Palmer 1999: 99-109).

\section{EL MUNDO INTELECTUAL COSTARRICENSE EN LA TRANSICIÓN}

\section{AL SIGLO XX}

La literatura costarricense apareció en la última década del siglo XIX, como parte de un proceso de construcción cultural de las elites intelectuales, que se apoyó primeramente en la tradición literaria costumbrista y anecdótica. El predominio de los cuadros costumbristas y la posterior aparición de literatura que utilizaba parámetros de creación y temas europeos, llevaron a la primera discusión teórica sobre las posibilidades de una literatura que tratara asuntos propios del país desde un punto de vista artístico. En 1894 tuvo lugar una polémica en torno al nacionalismo literario entre Carlos Gagini y Ricardo Fernández Guardia, el primero defendía lo nacional y el segundo lo europeo. Junto a Gagini, un grupo de escritores costarricenses concebían, de manera cada vez más consciente, la posibilidad de añadir a sus creaciones literarias el calificativo de "nacional" o “costarricense" (Quesada 1986: 93). La dinámica de los grupos intelectuales (a los que pertenecen los escritores costarricenses aquí analizados), sus conflictos internos y su relación con el poder político han sido objeto de estudio de diferentes investigadores.

Rogelio Sotela propone una clasificación de los escritores costarricenses de acuerdo con su fecha de nacimiento. Establece varias generaciones de escritores que, por pertenecer a un mismo grupo generacional, comparten similares formas estéticas y de 
pensar. Por ser "compañeros de letras" estos escritores comparten valores y visiones de mundo semejantes, y sus condiciones de vida son similares. A su modo de ver, la primera generación corresponde a los que nacieron hacia 1860, la segunda generación a los nacidos alrededor de 1875 , la tercera generación a los que nacieron cerca de 1885 y la cuarta generación a los que nacieron entre 1890 y 1895 (Sotela, 1923).

Un análisis más extenso lo realiza Álvaro Quesada (1998), quien plantea que el fracaso del modelo agroexportador y la crisis económica de la transición de siglo, suscitaron una transformación a nivel social: la sustitución de los "vestigios patriarcales" en lo económico, social y político, por un proyecto nuevo basado en temas sociales, de ideas anarquistas y socialistas, que se oponen a la pauperización y proletarización de los sectores populares. Este proceso de "descomposición social y moral", como fue representado por los autores tradicionalistas, permitió que los intelectuales identificaran el problema del imperialismo y de la dependencia económica. En este período, los intelectuales jóvenes se interesan por la aparición de una plebe urbana que llama su atención. En este proceso se conforman finalmente dos grupos: los intelectuales tradicionalistas, los llamados liberales del Olimpo (que se encuentra en un proceso de transición de oligarquía a burguesía), y los jóvenes intelectuales radicales que se unen con grupos populares para combatir el imperialismo, el gobierno liberal y plantear reformas políticas y sociales (Quesada 1998: 15-34).

La primera generación escribe en torno a los valores tradicionales y costumbres que se pierden y ensaya una representación realista de problemas morales y sociales que se producen al cambiar las costumbres y tradiciones por prácticas modernas. Denuncian la degradación del núcleo familiar patriarcal como analogía a la "descomposición” social y 
moral de la sociedad y tratan "motivos eróticos", que se refieren a temas como las relaciones extramaritales y la heterogamia como prácticas que amenazan el orden social existente (Quesada 1998: 49-50). Los textos tienden a conciliar la tradición con la ideología de progreso, sugiriendo que el equilibrio entre ambas se da a través de la educación (Quesada 1998: 53). Por otra parte, la segunda generación denuncia las tradiciones y costumbres "nacionales" como pertenecientes a una "oligarquía" e intentan incorporar en sus textos a otros grupos sociales anteriormente excluidos, como las mujeres y el pueblo. Estos intelectuales buscan en la teosofía, el anarquismo, el idealismo y el cristianismo socialista, nuevos modelos de convivencia y relaciones humanas alejados de la tradición oligárquica (Quesada 1998: 77-79). Denuncian problemas sociales mientras que describen un orden social regido por relaciones económicas opresoras o en forma vaga como destino o adversidad, autoridad impuesta por costumbres y tradiciones. En resumen, la segunda generación reformula los temas planteados por la primera generación, dándoles una nueva orientación de acuerdo con sus nuevas ideas (Quesada 1998: 95).

Por otro lado, la interpretación de Gerardo Morales (1993) propone que las limitaciones socioculturales de la República Oligárquica llevaron al surgimiento contestatario de una "nueva intelectualidad", cuyo discurso se basa en ideas anarquistas y socialistas pero también en una relación conflictiva con la cultura oligárquica. Este grupo de intelectuales promueven un modo de vida cultural que se opone al modelo elitista y conservador que predomina. Es decir, a partir de las limitaciones del proyecto político de sociedad y la estrechez del mercado cultural bajo el proyecto de cultura oligárquico- 
liberal, esta nueva intelectualidad crea un nuevo proyecto político de sociedad y cultura que incorpora nuevas ideologías y una nueva estética (Morales 1993: 76-80).

Iván Molina (1999) plantea que se dieron dos procesos paralelos: el primero fue la radicalización -de manera limitada- de algunos intelectuales a principios del siglo XX que difundieron ideas anarquistas y socialistas entre un sector de artesanos y obreros. Estos intelectuales fueron educados después de 1880, generalmente con becas estatales por provenir de familias de sectores medios, campesinas o artesanas y se formaron en un conflicto abierto con los intelectuales de generaciones anteriores. El segundo proceso, se dio cuando este grupo de intelectuales intentaron ampliar el mercado cultural, a partir de la utilización del discurso de la "cuestión social" en el contexto de la crisis económica de 1897-1907. Sin embargo, estos intelectuales no eran partidarios de las costumbres y creencias de los sectores populares y subestimaban sus estrategias de acción social y su capacidad de organización y lucha. Proponían la educación popular, en lugar de la civilización o la evangelización como forma de "redimir" a estos sectores (Molina 1999: $55-80)$.

Resumiendo, estas interpretaciones sugieren que en la transición hacia el siglo XX el círculo de intelectuales costarricenses se dividió en dos grupos: un primer grupo que responde a un proyecto cultural que se identifica con la ideología liberal y el progreso, cuyos miembros pertenecen a una clase alta y gozan de un espacio dentro del Estado. Un segundo grupo, que responde a un proyecto cultural que se identifica con la idearios socialistas y anarquistas y con la "cuestión social", cuyos miembros pertenecen a un sector social medio y luchan por ampliar el mercado cultural y ocupar un espacio dentro del Estado. 
Si bien observamos diferencias al interior del grupo de intelectuales costarricenses, existe una continuidad entre los planteamientos de ambas generaciones de reformistas positivistas; no obstante, se debe considerar la forma distinta de promover sus proyectos y de estructurar sus discursos. De este modo, la temática se puede agrupar en dos maneras de problematizar esta transición según sugieren los escritos literarios. Estas son: el "conflicto cultural", entendido como una crítica a la cultura de la élite; y el conflicto social, que incorpora a los sectores populares desde una perspectiva de clase.

\section{EL HOSPITAL NACIONAL DE LOCOS}

Con la constitución del Estado liberal, se crearon una serie de instituciones que llevaron a cabo una política de protección social complementaria a la labor realizada en la economía, y que partían de un enfoque positivista del intervencionismo estatal. Según Steven Palmer (1999), estas instituciones contemplaron una lógica propia dentro de su organización, y fueron originadas al margen del Estado por proyectos filantrópicos, de caridad pública, de derecho o de medicina. Sin embargo, fueron incorporadas a la política social planteada por el Estado liberal y concebidas nuevamente bajo la perspectiva positivista de un grupo intelectual de reformadores, que formaban parte de la burocracia estatal. El Hospital Nacional de Locos, creado en 1890 y luego conocido como Asilo Chapuí, fue una de las instituciones que respondieron a las exigencias de las reformas positivistas.

La necesidad de crear un Hospicio destinado a los enfermos mentales, se hizo evidente desde la segunda mitad del siglo XIX (Láchner 1902: 206), pues se registraba 
que el número de enfermos atendidos por el Hospital San Juan de Dios iba en aumento. Al igual que los enfermos mentales, leprosos y tuberculosos compartieron el mismo Hospital con otros dolientes; y aunque se tuviera conciencia de la necesidad de un tratamiento especial para estos enfermos, los recursos de las instituciones de caridad ni del Estado daban abasto para la construcción de nuevos hospitales. La Junta de Caridad intentó unificar los recursos en torno al Hospital San Juan de Dios, mediante la creación de una lotería en 1862, sin embargo esta medida no tuvo éxito (Chinchilla 1972: 101177). Posteriormente, al intensificarse los conflictos entre la Iglesia y el Estado liberal en la década de 1880, la beneficencia de la Iglesia católica debió ajustarse a las directrices de las reformas positivistas, recibiendo fondos públicos para el mantenimiento de sus instituciones y adoptando esquemas modernos de atención (Palmer 1999: 112). Los esfuerzos por reformar la administración de las instituciones de salud lograron ser efectivos hacia finales del siglo XIX, con el decreto de fundación del Hospicio Nacional de Locos y la Lotería Nacional, aprobados en 1885 durante el período presidencial de Bernardo Soto Alfaro.

El decreto de fundación de esta institución fue redactado por el Dr. Carlos Durán, un reconocido intelectual positivista con una amplia carrera burocrática. Este decreto establecía la centralización de la administración de las instituciones hospitalarias del país. De esta forma, los recursos provenientes de la Lotería Nacional serían administrados por la Junta de Caridad del Hospital San Juan de Dios; la cual, previa aprobación del Poder Ejecutivo, se encargaría de distribuirlos entre los hospitales de Alajuela, Cartago, Heredia, Puntarenas, Guanacaste, Limón y el Hospicio Nacional de Locos. Este decreto no sólo proponía un sistema para financiar la vigilancia de la salud (Palmer 1999: 105), 
mediante la labor de la Junta de Caridad, sino que también evocaba por una parte las funciones de Estado policía y por otra las de Estado protector, al fundar una institución destinada a atender y/o recluir a enfermos pobres. En este sentido el decreto considera

“...que el grado de cultura que ha alcanzado la República reclama la fundación de un asilo nacional de locos, que a la mayor brevedad posible, proporcione abrigo y asistencia a los que vagan por los caminos sin protección de ningún género, y con peligro para la tranquilidad de los habitantes..."1

En este discurso, el hospital fungía como asilo y como reclusorio; en la realidad, es posible que también. Según un estudio de pobreza urbana en la ciudad de San José que cubre el período entre 1890 y 1930, la mayoría de los internos del hospital pertenecían a sectores pobres (Briceño 1998: 185-216). El número de enfermos atendidos en el hospital aumentó progresivamente entre 1890 y 1930. En 1894 la institución atendía a 148 enfermos, en 1904 a 257 enfermos y en 1916 habían 485 internos (Briceño 1998: 190198). Las ocupaciones que predominan para los enfermos hombres son de jornaleros, en la industria y agricultores. En 1894 los jornaleros ocupaban un $41 \%$ del total de los internos, los trabajadores de la industria (entre ellos carpinteros, albañiles, herreros, carniceros, mecánicos, sastres, etc.) eran un $18 \%$ del total, y los agricultores un 14,5\% (Briceño 1998: 191). Para 1904, los jornaleros siguen siendo mayoría, un 56\% del total de internos hombres, mientras que los oficios de la industria conforman un $11 \%$. En este año el sector de "desocupados" iguala al de los agricultores con un 9,6\% (Briceño 1998: 194). Hacia 1916, los jornaleros siguen siendo el grupo mayoritario (42\% del total) mientras que los desocupados sobrepasan al sector de la industria y a los agricultores (Briceño 1998: 195-196). 
A partir de 1909, el número de mujeres internadas sobrepasaba al número de hombres (Briceño 1998: 189). Las ocupaciones que predominan para las internas en 1894 eran sirvientas $(33,8 \%$ del total de internas), jornaleras $(27,7 \%)$ y de oficios domésticos (24,6\%) (Briceño 1998: 192). En 1904, el sector de oficios domésticos aumentó al 45.5\% del total de enfermas, mientras que las jornaleras $(22,3 \%)$ y las sirvientas (16\%) disminuyeron. Para 1916, el sector de oficios domésticos y el de jornaleras se unifica en una sola categoría alcanzando un 74,5\% del total de las enfermas, el sector de sirvientas pasa a ser el 7,8\%, y la categoría de "sin oficio" pasa a ocupar un tercer lugar con 7,4\% del total (Briceño 1998: 197).

Estas ocupaciones evidencian que la mayoría de los enfermos internados en el hospital pertenecían a sectores populares, por lo que es muy probable que la institución cumpliera con su función de asistencia, pero a la vez es interesante notar el aumento en el número de enfermos y enfermas "desocupados" o "sin oficio." La imposibilidad de clasificarlos según su ocupación, puede indicar que los enfermos llegaron por sí solos (sin la compañía de un familiar), o que su enfermedad les impidió dedicarse a algún oficio a lo largo de su vida, o simplemente que fueron recogidos en las calles por la policía. Asistir o recluir, ¿cuál era la alternativa de más peso para los pobres con este tipo de padecimiento? Sin duda, muchos criterios con los cuales eran descritos los enfermos se definían a partir de la segunda opción; lo cual se refleja en el "Informe de la Junta de Caridad de San José" de 1906:

“...no podrá decirse, por esta vez a lo menos, que han sido los agricultores los que han dado el contingente mayor a nuestra casa, sino en primer término figuran los vagabundos, producto desgraciado de elementos sociales degenerados ya y por consiguiente destinados por ley ineludible de la suerte al presidio o al manicomio...", 
Un componente importante de este discurso era la ideología de "progreso", un pilar de las Reformas Liberales planteadas por los intelectuales del "Olimpo", con la intención de "civilizar" a las culturas populares. Modernizar era difundir los valores burgueses y capitalistas; pero también sanear, educar y controlar la sociedad, principalmente a los sectores populares hasta entonces poco conocidos por el Estado. En esta tarea, el criterio moral determinaba la dirección a seguir por parte de estos intelectuales positivistas, esto se refleja en los datos que presenta el médico Láchner Sandoval en la Revista de Costa Rica en el Siglo XIX, según los cuales y de acuerdo con las estadísticas del Hospital, en un $28 \%$ de los casos las causas de los trastornos mentales eran atribuidos al alcoholismo, mientras que en el $64 \%$ de los casos se debía al "método de vida, la educación y y la selección matrimonial", quedando un $8 \%$ de casos explicados por los abusos venéreos y del café, excitación política y religiosa, espiritismo, herencia, matrimonio entre parientes. ${ }^{3}$ Este médico además recomendaba una mayor responsabilidad de los padres para evitar la "defectuosa selección matrimonial." En otras palabras, era importante que los sectores populares (estrato de donde provenían la mayoría de enfermos internados en el hospital), comprendieran que la prevención de las enfermedades iba acompañada de una adecuada escogencia del "método de vida", la educación y la pareja; además de la abstinencia de sustancias estimulantes.

Las cifras oficiales de las causas de la locura en 1902, publicadas en la Gaceta Médica en 1903, son muy distintas de las que cita Láchner. La herencia ocupaba el primer lugar entre las causas de la locura; un $49,6 \%$ en las mujeres y $47,8 \%$ entre los hombres, para un $48,7 \%$ del total de enfermos (mientras que en las cifras dadas por Láchner ocupan un porcentaje muy pequeño). Llama la atención, que Láchner publicara 
estas cifras tan bajas en cuanto a la herencia, pues en la época las ideas eugenésicas empezaban a cobrar importancia (Flores 2000: 2). También, es curioso que el abuso de licor ocupara el segundo lugar en estas estadísticas con un 20,1\% del total de enfermos; siendo mayor el porcentaje entre los hombres $(28,7 \%)$ que entre las mujeres $(11,8 \% .)^{4}$ Es probable que Láchner modificara estas cifras, con la intención de llamar la atención sobre la necesidad de un cambio de conducta por parte de los sectores populares.

Resulta importante señalar que las causas que se atribuyeron a la locura en un nivel "terapéutico-científico" son similares a las nociones de locura que construyeron los intelectuales. Este primer esfuerzo estatal por controlar a los enfermos mentales se dio en el marco de las más variadas nociones de locura, donde criterios médicos y científicos se confundían y mezclaban con criterios socioculturales. De hecho, para la construcción de las nociones de "locura" en el discurso literario, en muchos casos los elementos socioculturales tuvieron más peso que los elementos médicos, como veremos más adelante.

3. LAS NOCIONES SOBRE ENFERMEDAD MENTAL Y "LOCURA" EN EL DISCURSO LITERARIO COSTARRICENSE

Es importante aclarar que el término "locura" es alusivo a criterios socio-culturales que se producen en las interacciones humanas, mientras que el concepto de "enfermedad mental" se restringe al ámbito biológico e involucra la reclusión institucional de un individuo con la intención de brindarle un tratamiento médico que transforme su condición de enfermedad (Coto y Ramírez 1985:59). Por esta razón, en el siguiente 
análisis de las obras literarias se ha utilizado alternativamente "padecimiento mental", para referirse indistintamente a la "locura" o a la "enfermedad mental."

\section{La "locura" como tema del conflicto cultural}

En este primer grupo de obras literarias es posible identificar lo que los autores definen por comportamiento normal y anormal, cuál es la interacción entre cuerpo, mente y sociedad, cuáles elementos socioculturales y/o médicos son utilizados para construir las nociones de "locura" y cómo las causas de la misma se relacionan con la respuesta social que proponen los autores.

La novela de Máximo Soto Hall El Problema (1899) es una obra famosa dentro de la narrativa costarricense; es considerada como la primera novela antiimperialista y paradójicamente defensora del proyecto nacional oligárquico. ${ }^{5}$ En ella se plantea de forma utópica la anexión de Centroamérica a Estados Unidos y la subordinación de la "raza latina" a la "raza sajona". Paralelamente, se relata la vida amorosa del personaje central, quien al regresar a su país proveniente de Francia; desplaza a su antiguo amor una mujer de "figura poética", perteneciente a su propia "raza" y que se describe como de "sensibilidad enfermiza"-, por su prima Emma -una mujer vigorosa de ascendencia sajona y de carácter fuerte-. En esta novela, Emma se comporta dentro de la normalidad al ser una persona que razona, trabaja y asume dentro de su identidad femenina el rol de esposa y madre. Por el contrario, Margarita es una mujer de clase social alta cuyo "temperamento nervioso" y falta de voluntad e indecisión la hacen muy influenciable. Margarita se comporta anormalmente, es "débil" y propensa al "nerviosismo", hace suyos 
los criterios ajenos, es influenciable y dócil. La relación que se establece entre el cuerpo, portador de los vicios o las virtudes de una raza, y la mente/espíritu que propicia la voluntad de acción dentro de los límites de la razón, se resuelve en un sociedad conflictiva donde predomina la lucha de las razas. Los adjetivos que emplea el autor para describir el desequilibrio mental revelan un peso mayor de los elementos socioculturales que de los médicos para construir las nociones de locura. Por ejemplo, se habla de un "temperamento nervioso," de un "apasionamiento," "vacilación" y "sensibilidad enfermiza."

En esta novela, la herencia es la causa principal de la "locura". El autor refuerza mediante el padecimiento mental de Margarita la debilidad de la "raza" latina frente a la sajona. Entre las causas de esa debilidad de la "raza", se citan la mala educación moral y social que no prepara a la "raza" latina para formar un hogar. Así,

“...Margarita era una neurasténica hasta el límite del histerismo; una enferma, una verdadera enferma. Había en ella una gran degeneración. Su padre la engendró ya viejo y gastado, su madre la concibió, agobiada por la nostalgia, herida de muerte por su suprema laxitud...En fatales condiciones vino al mundo y en vez de sujetarla a un régimen fortalecedor, enérgico, se le entregó a los refinamientos del hastío, se le acrecentó el mal..." (Soto 1992: 95-96).

La debilidad se acentúa en el cuerpo femenino, aunque a ello contribuyen razones de mayor peso como la "degeneración" presente en ella debido a causas hereditarias que se refuerzan con la floja educación recibida y una vida sin trabajo. El autor propone implícitamente criterios eugenésicos, al afirmar que: “...el pequeño, o mejor dicho, el infeliz, el enfermo, sentirá seducción del grande, del sano..." (Soto 1992: 118), y la exclusión como respuesta social: el protagonista excluye a la enferma de su vida. 
En la obra teatral de Eduardo Calsamiglia, El Combate (1914), Lucía es una mujer de clase alta que padece de tuberculosis sin saberlo. Arturo, su marido, es médico y dedica su vida a encontrar la cura de esta enfermedad. Sin embargo, Lucía también padece de "histerismo" y esta condición le permite pasar por alto algunas normas morales. Nuevamente, el comportamiento normal se define a partir del rol esperado que debe cumplir un individuo determinado en la sociedad. En este caso se espera que Lucía asuma su papel de esposa fiel y próximamente el de madre. Sin embargo, Lucía se deja llevar por sus sentimientos, frecuentemente asiste a los bailes y le es infiel a su marido. En esta obra teatral, el padecimiento mental se centra en la debilidad del cuerpo femenino y la docilidad de la mente femenina, más inconsciente que perversa. Ambos, cuerpo y mente femeninos, deben estar bajo el cuidado de los hombres (esposo, padre, suegro) para evitar que se corrompan.

En la construcción de las nociones de locura persisten los elementos no médicos como la "sensibilidad", pues se indica que Lucía es

“...una mujer que tiene los nervios a flor de epidermis. Un sistema nervioso impresionable hasta lo inverosímil. Casi...por qué no decirlo: casi una histérica. Su padre murió tuberculoso..." (Quesada 1993: 217).

Sin embargo, se introducen algunos términos médicos como el histerismo (enfermedad que se asociaba más con las mujeres) y al igual que en la novela anterior, los factores hereditarios contribuyen al desarrollo del padecimiento mental. Asimismo, este padecimiento acentúa la debilidad de la mujer como ser inconsciente e irreflexivo, contraponiéndolo a la figura del doctor, un hombre sensato que encuentra en la ciencia un arma eficaz en el combate contra la enfermedad de su esposa. Aún cuando su esposa le ha sido infiel; su honor 
“...está muy por encima de estólidas consideraciones y una pobre histérica, una débil enferma a quien se lo he confiado no lo desbarata a espaldas mías con un gesto, con un error; no puede desvirtuarlo con un desfallecimiento al que la empujaban su inconciencia, su educación y su idiosincrasia. Sólo en virtud de la más inverecunda de las filosofías queda la honra de un hombre como yo a merced de una mujer como ella..." (Quesada 1993: 253-254).

Este padecimiento mental está relacionado en parte con su herencia tísica, su educación como una dama de "sociedad" (de clase alta) y su naturaleza femenina. El autor enfatiza que su vida libertina al margen de la autoridad masculina la lleva a ser apartada de su vida familiar y de la sociedad. Finalmente, ella es recluida por su esposo/médico a una casa en el campo, para siempre.

Las dos piezas teatrales de Daniel Ureña guardan una relación especial con la "locura", en ellas se nota la evolución del autor hacia una concepción de la "locura" como discurso triunfante. En la obra Los Huérfanos (1910), se presenta la traición de una mujer a su esposo. Éste se da cuenta del adulterio través de un amigo; a quien su esposa culpa de difamador, a la vez que mancilla el honor de la mujer de este, Consuelo, haciendo creer a todos que ella lo engaña con otro. La mujer es asesinada y el hombre es encarcelado como culpable del crimen. Una carta de Consuelo, escrita desde el manicomio días antes de morir, tras recobrar la razón por gracia divina, aclara el asesinato y la confiesan como culpable.

En esta obra, otra vez lo normal se define como el comportamiento esperado de acuerdo al rol femenino determinado por la sociedad. En este caso lo normal es que una mujer asuma su papel de esposa y madre bajo la autoridad masculina, que en la obra viene a representar un modelo de virtud (el personaje de Justo). El adulterio y el asesinato cometido por los personajes femeninos son castigados con la muerte y la locura 
respectivamente. Este tipo de justicia poética, de interpretación del crimen y el castigo como una analogía de causa y efecto constituyen la moraleja de la obra.

A través de un espíritu sano se logra perpetrar una acción moralmente correcta, pues el autor sigue este razonamiento: “...mens sana, es decir, primero el espíritu sano; in corpore sano, el cuerpo fortalecido por la fuerza del espíritu..” (Ureña 1910: 25). En realidad, el espíritu sano suele ser el que porta el cuerpo masculino, mientras que el cuerpo femenino por su naturaleza tiende a ser corrompido más fácilmente. Así, la sociedad impone normas, el quebrantamiento de esas normas sociales lleva al sufrimiento, los espíritus débiles se dejan abatir por el sufrimiento y esto puede causarles la pérdida de la razón.

“...el cuerpo es como una caja armónica que humedecida ó deteriorada, hace sufrir á las piezas interiores cuyos sonidos resultan sordos al perder la densidad de las vibraciones. Así, el cuerpo enfermo parece apagar las dulces armonías del alma, y perciben nuestros oídos esas notas tristes de la existencia que marcha camino de la tumba..." (Ureña 1910: 8).

En esta obra, lo moral ocupa un espacio importante dentro de la definición de "locura", primero porque el comportamiento inmoral, como las relaciones sexuales extramaritales pueden provocar "perder la razón" y segundo porque la irracionalidad constituye un alejamiento de lo moral, pues asume que morir loco es morir en pecado y es necesaria la razón para lograr un arrepentimiento y una purificación del alma. Puede verse como en esta situación funciona la exclusión social como forma de apartar un elemento corrompido de la sociedad, primero con la deshonra y posteriormente con la reclusión en un manicomio.

Podemos ver que estos fragmentos del discurso literario tienen mucho en común. Por un lado asignan una connotación negativa al padecimiento mental que se fundamenta 
en la herencia, la mala educación moral y la corrupción de la mente y el cuerpo. Para ello se emplean personajes femeninos cuyos padecimientos mentales se relacionan con acciones moralmente incorrectas. Estos fragmentos, al igual que los dos siguientes, también reflejan la conflictividad existente al interior del grupo intelectual, pues critican el modelo de sociedad propuesto, los valores burgueses y el comportamiento de las clases altas.

En María del Rosario (1907) (Quesada 1993:149-215), Daniel Ureña le otorga una noción positiva a la "locura", esta vez en el personaje de perfil mesiánico de Andrés a quien llaman loco por sus ideas nobles y su voluntad de ayuda al prójimo; éste ha sido acogido en casa de Doña Chayito, por lo que es considerado como parte de la familia. Ricardo, hijo de Doña Chayito, deshonra a María del Rosario, una campesina humilde que había estudiado en un colegio de la capital. Jacinto, el padre de la muchacha ofendida, amenaza a Ricardo con cobrar su honor mediante un duelo, por lo que Ricardo huye fuera del país alentado por el consejo de su madre y de un amigo. Andrés interviene en favor de la muchacha y su familia e intenta consolarlos. Tiempo después, Jacinto muere y la familia de María del Rosario se deshace. Ella se convierte en una pordiosera que llega un día a la casa de Doña Chayito a cobrar su honor asesinando Ricardo.

En esta obra el loco masculino cumple un papel moralmente positivo, mientras que el tema de la "locura" se plantea desde el discurso de la razón. El comportamiento normal corresponde al egoísmo y de manera paradójica, el comportamiento anormal al altruismo. Andrés se comporta anormalmente porque se interesa y sufre por el mal ajeno, busca "lo útil, lo moral, lo sano;" es decir, es un ser "civilizado" en una sociedad donde predomina lo inútil, lo amoral y lo enfermo. 
Los pobres son bondadosos, pero infelices y sufren por la maldad de la gente rica pero acceden fácilmente al vicio y son corrompidos debido a su ignorancia (esto sucede con Jacinto, con el muchacho campesino que pretendía a María del Rosario y con ella misma). Por otro lado, los ricos a pesar de su educación y su filantropía son seres falsos que sólo buscan su propio bien y el de los suyos (esto sucede en la casa de doña Chayito, se observa en el comportamiento de Ricardo y en el comportamiento del amigo de Ricardo). En tanto que lo que distancia a Andrés de estos ricos y estos pobres es su intelecto, su educación, que le permite discernir entre bien y mal y vivir una vida moralmente correcta. Andrés propone un nuevo proyecto social de bienestar humano, que no se logra con la "civilización" o la "evangelización" de las personas, sino mediante la educación. Además, Andrés rechaza la caridad entendida como los proyectos filantrópicos de la clase alta y por su comportamiento es excluido de la familia de doña Chayito. Además, el autor introduce un elemento médico para construir la noción de locura: la "risa nerviosa" de Andrés es una señal de que su padecimiento mental no es imaginario, es una enfermedad.

En el cuento de Ricardo Fernández Guardia, Neurosis? (1894), Juan es un hombre joven, instruido, de clase social alta, incapaz de ser constante en alguna cosa. En París iba a estudiar medicina y luego decidió ser pintor; tiempo después abandonó París con la idea de ser músico. Cuando llegó a Costa Rica se vio obligado a trabajar en la hacienda de su padre, allí se enamoró de una muchacha a la que una vez conquistada traicionó por otra que no quería, ella se casó con otro y lo olvidó, por lo que en su despecho se entregó a las faenas agrícolas. Este cambio de quehaceres lo llevan a darse cuenta de que la 
inconstancia rige su carácter de manera involuntaria y que lo lleva a hacer "cosas disparatadas." Juan decide encerrarse en un monasterio en Italia.

Al igual que en el caso anterior, aquí vemos cómo se le asigna un valor positivo al padecimiento mental de un personaje masculino instruido. Juan no tiene un comportamiento normal, pues no lleva la vida deseada por sus padres; en cambio, sigue las exigencias de su naturaleza de "artista", y se constituye en una “...víctima de la enfermedad de nuestro siglo, de ese mal misterioso que puebla hospitales y manicomios con hombres de ingenio..." (Fernández 1894: 156). Con cierto humor, el autor plantea la existencia de una sociedad opresora que se impone sobre la mente creadora del intelectual. La noción de "locura" que utiliza el autor obedece tanto a criterios médicos como socioculturales: la "neurosis" se relaciona con un "desorden cerebral", pero también con una "enfermedad del alma." No obstante, los criterios médicos se ridiculizan y se acentúan los otros cuando el loco niega su locura

“...neurosis; pierde la chaveta algún pintamonas por tantas turcas como se ha puesto en la vida...neurosis. Estoy por creer que los franceses han inventado la palabreja para encubrir la falta de talento...” (Fernández 1894: 156).

Al final, el mismo loco se recluye pero para dedicarse a la tarea que considera suprema, ya no la ciencia, ya no el arte, si no la contemplación. La locura puede ser un estado del espíritu.

\section{Lo social en la literatura}

La "locura" como problema social fue considerada mucho antes de la creación de una institución especializada en el tratamiento de personas con padecimientos mentales. 
La caridad pública y privada se ocupó de ellos y en ocasiones la comunidad los aislaba en las casas o en las cárceles (Coto y Ramírez 1985: 64). Con la creación del Hospicio Nacional de Locos, la práctica de reclusión se desarrolló en un contexto científicopsiquiátrico que pretendió hacer objetivo el concepto de enfermedad mental a través de un proceso de "eugenización" del cuerpo social (Flores 2000:2). Los siguientes textos literarios analizados abordan la "locura" desde una perspectiva social, y aunque incluye elementos socioculturales para definirla, se apoyan en el entendimiento del padecimiento mental como una enfermedad, es decir, que responde a factores biológicos. Al igual que la mayoría de los enfermos mentales que son atendidos en el Asilo Chapuí, estos personajes locos pertenecen a sectores sociales populares y enfrentan grandes limitaciones económicas.

A finales del siglo XIX se aceleró el proceso de expropiación de pequeños propietarios; mientras que la incipiente proletarización permitió la formación de una "plebe" urbana, compuesta por clases trabajadoras que recibían bajos salarios y sufrían explotación e inseguridad laboral (Quesada 1998: 74). En las primeras décadas del siglo $\mathrm{XX}$, las presiones económicas se canalizaron en los sectores populares mediante la organización de movimientos sociales de obreros y campesinos que empezaron a politizarse. En la ciudad, artesanos y obreros se organizan en gremios y asociaciones de ayuda mutua, en el interior de los cuales empezaron a predominar -con un claro matiz político- los intereses obreros sobre los artesanos (Oliva 1992: 33). Las agitaciones sociales y la organización de las clases trabajadoras llevaron a algunos intelectuales a percibir una sociedad dividida en la cual las clases trabajadoras y los mismos intelectuales se consideraban grupos subordinados (Morales 1993: 114). ${ }^{6}$ Desde esta 
perspectiva, estos textos fueron concebidos por estos intelectuales como un aporte a la construcción de la "cuestión social", en la medida en que denuncian las condiciones socioeconómicas de sectores marginados. En las cuatro narraciones, los personajes "locos" son personas de clase social baja que viven de la caridad de sus vecinos o familiares. Su condición de "locura" está asociada a su posición socioeconómica que coarta las posibilidades de estos enfermos de acceder a mejores condiciones de vida.

El hambre es una víbora que estrangula el hogar del campesino, esta es la metáfora que utiliza Sánchez Bonilla en su cuento "El Conchito Enfermo" (Anto Relato 1989: 169172), para describir la vida cotidiana del campesino explotado. La miseria, la enfermedad, el hambre; pero también la bondad y la humildad "natural" del campesino formaron parte de los retratos de pobres en el marco del discurso de la "cuestión social." Como indicamos arriba, los siguientes autores retratan la locura desde la perspectiva de personajes de clase social baja y asociando el padecimiento mental con una enfermedad biológica. Esta generación de autores, que forman parte de la "nueva intelectualidad" que plantea Gerardo Morales, estaban más familiarizados con la psicología y la ciencia médica, menos imbuidos por el conflicto con la cultura oligárquico conservadora, por lo que no enfatizan lo moral como causa directa o indirecta del padecimiento mental, sino que se centran en la realidad material de los sectores populares.

El cuento de Manuel Argüello Mora La loca de la Avenida Central (1899), aunque no forma parte del discurso de la "cuestión social", manifiesta una continuidad con los planteamientos de los otros cuentos, pues enfoca el padecimiento mental desde una perspectiva social. Describe a la "loca", en primer término como una madre, que desde su sufrimiento expresa la injusticia de la marginación social. Lucía, tras la muerte de su hijo, 
empieza a tener alucinaciones y a perder conciencia de sí misma, por lo que es atendida en el Hospital Nacional de Locos; sin embargo, ella considera que en realidad no está loca y que el tratamiento que le dan le causa más sufrimiento. Esta mujer/madre de clase social baja tiene voz propia dentro de la narración con la cual denuncia su propio desamparo dentro de una institución estatal, pues al referirle al narrador su historia le pide que no la delate porque los doctores, dice ella, “...me martirizan dándome bromuro: el doctor que nos cura no tiene hijos..." (Argüello 1963: 209). El autor además ubica las causas del padecimiento mental en el sufrimiento por la pérdida de un ser querido, e introduce elementos médicos en la construcción de la noción de locura, como el bromuro que los doctores dan a Lucía y las pesadillas y alucinaciones que padece

“...duermo poco y sueño constantemente con un cilindro helado que toma diferentes formas, pero siempre en estado de hielo. Este cilindro a veces saca dos ruedas por los lados y dos caballos por un extremo...Luego aparece mi niño debajo de todo..." (Argüello 1963: 208).

Es interesante preguntarse por qué este escritor, un intelectual positivista claramente identificable con la "primera generación", cuestiona la labor social del Estado. Sin duda, la desconfianza hacia el asilo podían compartirla muchas personas, pues los diagnósticos no eran claros y algunos métodos curativos empleados como el susto, la intimidación, las sangrías y vómitos, los azotes, la silla giratoria y la castración (Coto y Ramírez 1985: 69), sugerían que los enfermos mentales eran torturados. Habría que determinar hasta qué punto se llevaron a cabo estas prácticas curativas, y cuál era la dinámica entre pacientes y médicos dentro de la institución.

De manera similar la narración de Joaquín García Monge, cuestiona la labor de la institución hospitalaria, pero este texto se enmarca dentro del discurso de la "cuestión 
social." En el cuento "El loquito" (La Mala Sombra, 1918), el loco es un personaje masculino joven de clase social baja que vive bajo el cuidado de su familia. La causa de su locura fue un susto que cambió su forma de comportarse

“...anda en camisa, porque no le paran los pantalones; los hace trizas o los deja perdidos. Arranca monte, cebollas, matas de café, de maíz, cuanto halla. Mira lo que hace, sonríe y da voces de contento..." (García 1994: 155).

El narrador se compadece de su estado y sugiere a su familia que lo envíen al asilo, por lo que el padre de éste se niega alegando que allí puede que no le cuiden bien. Este punto de vista lo comparte también el autor, pues deja ver que la forma de comportarse del "loquito" es inofensiva por lo que no tiene caso aislarlo de su ambiente familiar que, aunque de condición humilde, alberga altos valores humanos.

"El Conchito Enfermo" (Geranios Rojos, 1908) de Gonzalo Sánchez Bonilla (Quesada 1989: 169-172), narra la tragedia de Soto, un campesino pobre que vive en un rancho con su mujer. Ambos trabajan, él en un beneficio y ella en el cafetal, y a diario Soto se queja de las injusticias de su patrón y se cuestiona la justificación del cura sobre la existencia de la injusticia social y la explotación. Su hijo mayor, Sotillo, debe abandonar la escuela para ayudar en su casa, así que va a trabajar a un trapiche. Pronto adquiere una pulmonía y se muere. Soto enloquece pues cree que lo ocurrido es culpa suya. El autor propone que la causa inmediata de la locura de Soto es dolor provocado por la muerte de su hijo, pero la causa indirecta es la explotación del campesino, porque “...ंqué culpa puede tener un hombre que vive explotado en una sociedad, en donde le disipan el perfume de sus fuerzas?" (Quesada 1989: 171). Este texto también utiliza un elemento médico para construir la noción de locura: la risa histérica de Soto cuando 
finalmente lo domina la locura. A diferencia de los otros autores de este apartado, este autor concibe la locura como un proceso gradual, ¿del cual forma parte la explotación?

En el cuento "Moreira" (Por el amor de Dios, 1918) de Luis Dobles Segreda (Dobles 1993: 11-20), nuevamente el loco es representado por un muchacho de clase social baja; pero esta vez el "loco" representa un peligro potencial para las autoridades: deambula por las calles. Moreira comparte las buenas cualidades de las clases populares: es un hombre trabajador, honrado, "manso de corazón" y amante de su familia. Se dedicaba a pintar el templo de la comunidad y una vez llegó a trabajar sin haber desayunado, se desmayó y cayó del andamio. Al golpearse la cabeza quedó "tonto" y no pudo trabajar más. Vive de la caridad ajena sin molestar a nadie, el narrador insiste en llamarlo un "hombre sin pecados." Además de su padecimiento mental, el tiene que luchar contra el hambre, la miseria y la indiferencia de todos. Los "locos" como Moreira, que deambulaban por las calles, formaban parte del discurso liberal al que respondía el Estado policía, que insistía en la necesidad de preservar el orden y contener los elementos dañinos y peligrosos de la sociedad.

Sin embargo, el desconocimiento sobre los padecimientos mentales, hacía que las autoridades en muchos casos no fueran capaces de medir la peligrosidad de un "loco." Es interesante observar la forma en que el autor describe la relación entre el "loco" y la policía: no es del todo represiva sino también caritativa. Al poner el autor su mano sobre el hombro del loco este se estremece, “... ¿recuerda que así se la ha puesto también la policía para espantarlo?” (Dobles 1993: 13). Y en otra ocasión, “...la policía fue una vez a traerlo del rancho para el Hospital, con un ataque cardíaco; otro día volverá a llevarlo a dormir junto a Rafaela, (su madre) en el campo de los cipreses...” (Dobles 1993: 19). 


\section{CONCLUSIONES}

El enfoque positivista del intervencionismo estatal se preocupó por la protección del cuerpo social y por vigilar su salud promoviendo campañas de salubridad pública e higiene sobre la base del sistema educativo. También se propuso la creación de instituciones que sirvieran para dichos fines dentro de un esquema de atención moderno. El Asilo Chapui intentó ser desde su fundación una institución modelo, cuyas prácticas médicas se encontraban a la vanguardia de la ciencia psiquiátrica, al lado de una propuesta humanitaria de atención de los enfermos. En este proceso de promoción de instituciones de protección social dentro del Estado liberal por parte de los intelectuales positivistas, podemos identificar diferentes discursos que cuestionan y/o proponen proyectos político-culturales distintos para alcanzar la modernidad, dentro de un escenario de transición.

En el primer grupo de obras literarias analizadas, se utilizan más elementos socioculturales que médicos para construir las nociones de locura. Estas obras se enmarcan dentro del conflicto cultural e intergeneracional que agita el círculo intelectual de este período. La moral toma una dimensión importante en la construcción de estas nociones de locura. Vemos que en los textos se presentan personajes "locos" de clase social alta, que se desenvuelven en ambientes caracterizados por la pérdida de los valores morales y la vida fácil. Esta postura señala la mala educación moral y la herencia como factores formadores de una voluntad débil, un temperamento nervioso y un padecimiento mental que dificultan la incorporación de los personajes a la sociedad. Esto generalmente se da en el contexto de un núcleo familiar problemático, donde predominan relaciones de 
pareja marcadas por la infidelidad o entre parientes cercanos. La "locura" en los hombres acentúa características positivas, de creación intelectual; mientras que en las mujeres refuerza juicios de debilidad y corrupción moral. Además, los autores sugieren la reclusión como respuesta social al problema de la locura moral. Aquí podemos señalar una continuidad entre las propuestas de Daniel Ureña y Eduardo Calsimiglia, que corresponden a intelectuales identificados con las ideas de la "nueva intelectualidad", y las de Máximo Soto Hall y Ricardo Fernández Guardia, intelectuales identificados con el proyecto político-cultural liberal: ambos sugieren una crítica de los valores burgueses.

En el segundo grupo de obras literarias analizadas, pesan más los elementos médicos que los elementos socioculturales en la construcción de las nociones de locura. Estas obras tiene una perspectiva social del padecimiento mental y todas -excepto la de Manuel Argüello Mora- se enmarcan dentro de la construcción de la "cuestión social."

Estos textos presentan personajes "locos" pobres, pertenecientes a las clases trabajadoras y que exhiben los más altos valores de las clases populares. En ellos, la causa última de su "locura" se encuentra en sus limitaciones económicas y su situación de miseria. Se cuestiona la indiferencia como respuesta social y se propone la caridad. Además se exalta la pasividad y poca peligrosidad de estos personajes que deambulan por las calles. En este sentido, la percepción de los escritores es distinta de la de los textos oficiales. También, se cuestiona la labor del asilo y la reclusión en una institución estatal; que en el marco de la construcción de la "cuestión social", sería importante preguntarse si este rechazo constituye una estrategia para desconocer el esfuerzo estatal por incursionar en política social. 
Sobre el eje de estos discursos, el discurso literario construye nociones sobre la enfermedad mental y la locura, que responden; por un lado, a un llamado "conflicto cultural" en el cual, a pesar de la pretendida crítica a los valores tradicionales, se refuerzan los esquemas morales en relación con el género, asignando valores positivos a los hombres y valores negativos a las mujeres, y por otro, a una creciente visibilización de los conflictos de clase.

Finalmente, nos interesa señalar que en el proceso de construcción de las nociones acerca del padecimiento mental es ejemplar la marcada diferenciación de los temas: si se escribe sobre el conflicto cultural la "locura" adquiere un matiz sociocultural, que es preferido generalmente por escritores de sectores sociales altos que se concentran en problematizar su entorno social; mientras que los escritores de sectores medios se inclinan por los temas en los cuales se presentan conflictos socioeconómicos, e incluyen en la discusión a personajes de sectores populares que tienden a idealizar. Es notable que la problemática de género esté presente en el primer caso, mientras que en el segundo se invisibiliza para dar cabida a los conflictos de clase.

\section{BIBLIOGRAFÍA}

Argüello Mora, Manuel. 1963. "La loca de la Avenida Central." Obras literarias e históricas. San José: Editorial Costa Rica, pp. 207-209.

Briceño, César, et. al. 1998. "Pobreza urbana en Costa Rica 1890-1930. El caso de la ciudad de San José.” Seminario de Graduación, Universidad de Costa Rica.

Coto Campos, María y Ramírez Montes Ana. 1985. "Las políticas estatales en el campo de la salud y la enfermedad mental en Costa Rica 1940-1980." Tesis de Licenciatura en Psicología, Universidad de Costa Rica.

Chinchilla Gutiérrez, Sara. 1972. "La lepra en Costa Rica. Contribución a la Historia de la Medicina Nacional." Tesis de Licenciatura en Historia, UCR.

Dobles Segrega, Luis. 1993. "Moreira” Por el Amor de Dios. San José: Guayacán. 
Flores González, Mercedes. 2000. "Mujer y locura en la transición al siglo XX. La interpretación de texto como lectura de una experiencia social." Jornadas de Investigación del 21 al 25 de agosto-2000. San José: Instituto de Investigaciones Sociales, UCR.

Fernández Guardia, Ricardo. 1894. “Neurosis?” Hojarasca. San José: Tipografía Nacional, pp.129-159.

Fumero, Patricia. 1992. "La ciudad en la aldea: actividades y diversiones urbanas en San José a mediados del siglo XIX." Héroes al gusto y libros de moda: sociedad y cambio cultural en Costa Rica (1750-1900) San José: Editorial Porvenir, Plumsock Mesoamerican Studies, pp. 93-104.

García Monge, Joaquín. 1994. "El Loquito” Breviario Literario. San José: Editorial Costa Rica, pp.155-157.

González Murillo, Gonzalo. 1979. "Breve Estudio Histórico sobre el quehacer médicopsicológico en Costa Rica." La Psiquiatría y la Psicología en Costa Rica. San José: EUNED, pp.154-155.

Láchner Sandoval, Vicente. 1902. "Apuntes de Higiene Pública.” Revista de Costa Rica en el siglo XX. Tomo I. San José: Tipografía Nacional.

Molina Jiménez, Iván. 1995. El que quiera divertirse. Libros y sociedad en Costa Rica (1750-1914) San José: Editorial UCR.

1999. "Plumas y Pinceles. Los Escritores y los Pintores Costarricenses: Entre la Identidad Nacional y la Cuestión Social." Revista Historia de América, No.124, pp.55-80.

Molina, Iván y Palmer, Steven. 1997. Historia de Costa Rica: breve, actualizada y con ilustraciones. San José: Editorial UCR.

Morales, Gerardo. 1993. Cultura oligárquica y nueva intelectualidad en Costa Rica: 1880-1914. Heredia: Editorial UNA.

Oliva, Mario. 1992. Movimientos Sociales en Costa Rica (1825-1930) San José: EUNED.

Palmer, Steven. 1999. "Adiós Laissez-Faire: la política social en Costa Rica, 1880-1940." Revista Historia de América. México, No.124, pp. 99-117.

Quesada Soto, Álvaro. 1986. La formación de la narrativa nacional costarricense. San José: Editorial de la UCR.

1988. La Voz Desgarrada. La Crisis del discurso oligárquico y la narrativa costarricense (1917-1919) San José: Editorial de la Universidad de Costa Rica.

1998. Uno y los Otros: identidad y literatura en Costa Rica 1890-1940. San José: Editorial UCR.

ed. 1989. Antología del relato costarricense (1890-1930) San José: Editorial UCR.

, ed. 1993. Antología del Teatro Costarricense 1890-1950. San José: Editorial de la UCR. pp. 149-265.

Sotela, Rogelio. 1923. Escritores y poetas de Costa Rica. San José: Imprenta Lehmann.

Soto Hall, Máximo. 1992. El Problema. San José: Editorial UCR.

Ureña, Daniel. 1910. Los Huérfanos. San José: Imprenta Alsina. 


\section{NOTAS}

\footnotetext{
${ }^{1}$ Una transcripción del Decreto XXXVI de 1885 se encuentra en González 1979: 154-155.

${ }^{2}$ Informe de la Junta de Caridad de San José, 1906, citado por Briceño 1998: 186.

3 (Láchner 1902: 206). El autor no menciona para cuál año se aplican estas estadísticas, es probable que sean de 1902 o un año anterior cercano a esta fecha.

${ }^{4}$ Gaceta Médica, No 11. Agosto, 1903, p. 267.

${ }^{5}$ Quesada Soto, Álvaro. "El Problema en el contexto costarricense" (Soto 1992: 15-16).

${ }^{6}$ Recordemos que los intelectuales a los que se refiere Morales, pertenecen a lo que el llama "segunda generación"; provienen de sectores sociales medios y buscan un espacio en el aparato estatal para desarrollar se propio proyecto político.
} 